\title{
Efficacy of mangrove leaf powder for bioremediation of chromium (VI) from aqueous solutions: kinetic and thermodynamic evaluation
}

\author{
Thadikamala Sathish $\cdot$ N. V. Vinithkumar • \\ G. Dharani · R. Kirubagaran
}

Received: 13 November 2013/Accepted: 4 March 2014/Published online: 19 March 2014

(C) The Author(s) 2014. This article is published with open access at Springerlink.com

\begin{abstract}
Biosorption of heavy metals by bio-materials has been posited as a potential alternative to the existing physicochemical technologies for detoxification and recovery of toxic and valuable metals from wastewaters. In this context, the role of mangrove leaf powder (MLP) as biosorbent for chromium removal was investigated. In the present study, the effect of process parameters such as particle size, solution $\mathrm{pH}$, initial concentration of $\mathrm{Cr}(\mathrm{VI})$ ion and adsorbent dose on chromium removal by MLP was investigated. The maximum sorption was observed at particle size $0.5 \mathrm{~mm}$ and $\mathrm{pH}$ 2.0. The adsorption data follow the pseudo second-order kinetics model. The isotherms denote that Langmuir model is the best fitted than Freundlich model. The maximum adsorption capacity $\left(Q^{0}\right)$ of $60.24 \mathrm{mg} / \mathrm{g}$ of $\mathrm{Cr}(\mathrm{VI})$ at $30 \mathrm{~min}$ on MLP was determined using the Langmuir model. The adsorption isotherm model indicates that the chromium is adsorbing as monolayer on the surface of MLP with heterogeneous energetic distribution of active sites. Various thermodynamic parameters, such as Gibb's free energy $\left(\Delta G^{\circ}\right)$, enthalpy $\left(\Delta H^{\circ}\right)$ and entropy $\left(\Delta S^{\circ}\right)$ have been calculated. The thermodynamic data revealed that the adsorption of chromium ions onto MLP is endothermic in nature and a spontaneous process. The results of the present study suggest that MLP is an
\end{abstract}

T. Sathish $(\bowtie) \cdot$ N. V. Vinithkumar

Andaman and Nicobar Centre for Ocean Science and Technology, ESSO-National Institute of Ocean Technology, Port Blair 744103, India

e-mail: satish.tadikamalla@gmail.com

G. Dharani · R. Kirubagaran

ESSO-National Institute of Ocean Technology (Ministry of Earth Sciences, Government of India), Pallikarani,

Chennai 600 100, India effective bioremediation measure for removal of high concentration of $\mathrm{Cr}(\mathrm{VI})$ in waste waters.

Keywords Heavy metals - Adsorption - Mangrove leaf . Isotherms $\cdot$ Andaman and Nicobar islands

\section{Introduction}

Heavy metal release to the environment has been increasing continuously as a result of industrial activities and technological development, posing a significant threat to the environment, public and soil health (Cerbasi and Yetis 2001). Among the heavy metals released into environment, chromium is an important pollutant. Chromium is a redox active element, with oxidation states from -2 to +6 , but only the +3 and +6 states are prevalent in the aqueous environment. $\mathrm{Cr}(\mathrm{III})$ and $\mathrm{Cr}(\mathrm{VI})$ are environmentally stable oxidation states and exhibit different types of toxicity mechanism on biota. Chromium is released into the environment by a large number of industries such as mining, iron sheet cleaning, chrome plating, leather tanning and wood preservation (Krishna and Philip 2005). These industries contain $\mathrm{Cr}(\mathrm{III})$ and $\mathrm{Cr}(\mathrm{VI})$ at a concentration ranging from 10 to $100 \mathrm{mg} / \mathrm{L}$ (Park et al. 2005). Long-term release of such wastewater may result in the accumulation of heavy metals in soil exerting a selection pressure on soil micro-biota.

$\mathrm{Cr}(\mathrm{VI})$ is a highly soluble and toxic chromate anion, and is a suspected carcinogen and mutagen (Costa 2003). The conventional methods for removing $\mathrm{Cr}(\mathrm{VI})$ ions from wastewater are based on the combination of different physical and chemical reduction processes (Kurniawan et al. 2006). However, such processes are becoming undesirable due to the use of expensive and toxic chemicals. 
Further these methods are also inefficient in the removal of $\mathrm{Cr}$ (VI), particularly with wastewater containing with a low $\mathrm{Cr}$ concentration and also associated with the production of secondary effluents (Baral and Engelken 2002).

Prakasham et al. (1999) and Kadimpati et al. (2013) suggested that the removal of heavy metals by adsorption on various biomass surfaces is the best alternative to the physico and chemical methods. In recent years, many researchers used the various bio-materials such as tea factory waste (Cay et al. 2004; Malkoc and Nuhoglu 2005, 2006), sawdust (Acar and Malkoc 2004; Yu et al. 2003), soya cake (Daneshvar et al. 2002), sugar cane bagasse (Gupta and Ali 2004), green algae (Gupta et al. 2001; Malkoc and Nuhoglu 2003), distillery sludge (Selvaraj et al. 2003) for removal of heavy metals from waste waters. Most of the low-cost sorbents have the limitation of poor sorptive capacity, and thereby, for the same degree of treatment it generates more solid waste (pollutant laden sorbent after treatment) leading to disposal problems. Therefore, there is a need to explore low cost, economically viable and effective sorbent, having high pollutant sorption capacity (Ho et al. 2005).

Andaman and Nicobar (A \& N) archipelago is one of the mega-biodiversity hotspots of India. The archipelago consists of 572 islands, located in the Bay of Bengal, lying between $6^{\circ} 45^{\prime}-13^{\circ} 45^{\prime} \mathrm{N}$ and $92^{\circ} 12^{\prime}-93^{\circ} 57^{\prime} \mathrm{E}$ in the IndoBurmese microplate junction. The islands are spread over a distance of $1,120 \mathrm{~km}$ with a coast line of $1,962 \mathrm{~km}$. The close proximity of these groups of islands to the equator and the irregular and deeply indented coast line, creeks, bays and estuaries facilitate the rich and diverse mangrove forests. Rozaini et al. (2010) reported that mangrove bark has a potent adsorbent for $\mathrm{Ni}$ (II) and $\mathrm{Cu}$ (II) ions from aqueous solutions. The current study was aimed to determine the capability of mangrove leaves from A \& $\mathrm{N}$ islands as a potent adsorbent to remove the chromium (VI) from aqueous solutions.

\section{Materials and methods}

\section{Collection and processing of adsorbent}

In the present study mangrove leaf powder (MLP) (biomass) was used as adsorbent for chromium removal. The sorbent material, mangrove leaves (Avicennia marina) was collected from mangrove plants located in the Minnie Bay area, Port Blair, A \& N islands, India. The collected leaves were shade dried and then powdered in a pulverizer. The dirt and color components were removed by washing with distilled water until a colorless solution of MLP was obtained. Processed MLP was shade dried and sieved to obtain the desired particle size $(1.4-0.25$ and $<0.25 \mathrm{~mm})$.
Sorption studies

The vibrant behavior of adsorption was explored based on the effect of particle size (1.4-0.25 and $<0.25 \mathrm{~mm})$, effect of $\mathrm{pH}(2-8)$, metal ion concentration (100-600 mg/L), amount of biomass $(2-10 \mathrm{~g} / \mathrm{L})$ and temperature $\left(10-40{ }^{\circ} \mathrm{C}\right)$. Experiments were conducted in a batch system in $250-\mathrm{mL}$ Erlenmeyer flasks containing $100 \mathrm{~mL}$ of the adsorption solution (with desired concentration and $\mathrm{pH}$ ) and anticipated MLP concentration. The initial $\mathrm{pH}$ adjustments were carried out using the $1 \mathrm{~N} \mathrm{HCl}$ and $1 \mathrm{~N} \mathrm{NaOH}$. The flasks were agitated on a rotary shaker at $70 \mathrm{rpm}$, the samples were taken to determine the residual $\mathrm{Cr}(\mathrm{VI})$ concentration in the solution at predetermined time intervals. The sorbent material was separated from the solution by filtration through Whatman No. 1 filter paper and the metal concentration was determined in the filtrate. The amount of metal adsorbed was determined by calculating the difference between the initial $\mathrm{Cr}(\mathrm{VI})$ concentration and remnant in filtrate.

\section{Analytical method}

The $\mathrm{Cr}(\mathrm{VI})$ loading on sorbents was computed based on mass balance through the loss of metal from aqueous solution. $\mathrm{Cr}(\mathrm{VI})$ concentration in aqueous phase was estimated by diphenyl carbazide method (APHA 1985). Cr(VI) reacts with diphenyl carbazid, which forms a red-violet colored complex. The absorbance of the colored complex was measured in a double beam UV-visible spectrophotometer at $540 \mathrm{~nm}$ wavelength (Lambda 25, Perkin Elmer).

Kinetic modeling

Adsorption kinetics play a vital role in the scale-up studies of waste water treatment process design. These designs give a chance to pick the optimum operational conditions of heavy metals and sorbent to facilitate the effective adsorption process at large-scale processes.

It was assumed that the adsorption of chromium from liquid to MLP was a reversible reaction with an equilibrium state being established between two phases. To correlate the rates of reaction a simple first-order, pseudo firstorder and pseudo second-order models were used (Hamadia et al. 2001).

The first-order rate constants were calculated using the following equations:

$\ln [1-U(t)]=-k_{\mathrm{r}}^{\prime} t$

where $U(t)$ fractional attainment of equilibrium, $k_{\mathrm{r}}^{\prime}$ overall rate constant, $t$ time

$U(t)=\frac{X_{\mathrm{A}}}{X_{\mathrm{A}_{\mathrm{e}}}}$ 
$X_{\mathrm{A}}$ the fractional conversion of adsorbate, $X_{\mathrm{A}_{\mathrm{e}}}$ the fractional conversion of adsorbate at equilibrium

$k_{\mathrm{r}}^{\prime}=k_{1}\left(1+\frac{1}{K_{\mathrm{c}}}\right)=k_{1}+k_{2}$

$K_{\mathrm{c}}$ equilibrium constant was calculated based on the following equation:

$K_{\mathrm{c}}=\frac{C_{\mathrm{B}_{\mathrm{e}}}}{C_{\mathrm{A}_{\mathrm{e}}}}$

$C_{\mathrm{B}_{\mathrm{e}}}$ and $C_{\mathrm{A}_{\mathrm{e}}}$ are the concentrations for chromium on the sorbent and solution at equilibrium.

The pseudo first-order rate constants were determined using the following equation:

$\log \left(q_{\mathrm{e}}-q\right)=\log \left(q_{\mathrm{e}}\right)-\frac{k_{1}^{\prime}}{2.303} t$

where $q_{\mathrm{e}}$ amount of solute adsorbed per unit weight of adsorbent $(\mathrm{mg} / \mathrm{g})$ at equilibrium, $q$ amount of solute adsorbed per unit weight of adsorbent $(\mathrm{mg} / \mathrm{g})$ at time $t, k_{1}^{\prime}$ adsorption constant calculated from the slope of plot between the time and $\log \left(q_{\mathrm{e}}-q\right)$.

The following equation was used to determine the pseudo second-order constant:

$\frac{t}{q}=\frac{1}{k_{2}^{\prime} q_{\mathrm{e}}^{2}}+\frac{1}{q_{\mathrm{e}}} t$

where $k_{2}^{\prime}$ second-order rate constant.

The initial sorption rate $(h)(\mathrm{mg} / \mathrm{g} / \mathrm{min})$ was calculated using the following equation

$h=k_{2}^{\prime} q_{\mathrm{e}}^{2}$.

The rate constants were obtained from the kinetic plots of Eqs. (1), (5) and (6) correspondingly.

\section{Adsorption isotherm}

An adsorption isotherm was used to characterize the interactions of sorbent molecule with the adsorbent material. The adsorption model assumes that the species are adsorbed at a fixed number of well-defined sites, each of which is capable of holding only one molecule. These sites are also assumed to be energetically equivalent and distant from each other so that there are no interactions between molecules adsorbed on adjacent sites. Adsorption equilibrium is called as adsorption isotherm and is obtained by plotting solute (adsorbate) concentration in the solid phase as a function of solute concentration in liquid phase at a given temperature.

To describe the adsorption equilibrium between chromium and MLP, Langmuir and Freundlich equations were used. The empirical Freundlich equation is as follows:
$q_{\mathrm{e}}=\mathrm{K}_{\mathrm{f}}\left(C_{\mathrm{e}}\right)^{1 / n}$

$C_{\mathrm{e}}$ equilibrium concentration $(\mathrm{mg} / \mathrm{L}), K_{\mathrm{f}}$ equilibrium constant for adsorption capacity, $n$ equilibrium constant for adsorption intensity.

To calculate the $K_{\mathrm{f}}$ and $\mathrm{n}$ the Eq. (8) was linearized. The logarithmic form of Eq. (8) is follows as

$\ln q_{\mathrm{e}}=\ln K_{\mathrm{f}}+\frac{1}{n} \ln C_{\mathrm{e}}$.

The linear form of Langmuir isotherm model is

$\frac{C_{\mathrm{e}}}{q_{\mathrm{e}}}=\frac{1}{Q^{0} b}+\frac{C_{\mathrm{e}}}{Q^{0}}$

$b$ constant related to the energy or net enthalpy of adsorption $(1 / \mathrm{mg}), Q^{0}$ constant related to adsorption capacity $(\mathrm{mg} / \mathrm{g})$ at equilibrium.

Langmuir constants were obtained from the slope and intercept of linear plot of $C_{\mathrm{e}} / q_{\mathrm{e}}$ versus $C_{\mathrm{e}}$.

Equilibrium parameter or separation factor $\left(R_{\mathrm{L}}\right)$ is a dimensionless constant which is an essential characteristic of Langmuir isotherm. $R_{\mathrm{L}}$ value indicates the type of isotherm. The $R_{\mathrm{L}}$ was determined using the following equation:

$R_{\mathrm{L}}=\frac{1}{1+b C_{0}}$

where $b$ Langmuir constant obtained from the Eq. (10), $C_{0}$ the initial metal ion concentration $(\mathrm{mg} / \mathrm{L}), R_{\mathrm{L}}$ values between 0 and 1 indicate favorable adsorption.

Estimation of thermodynamic parameters

Using the following equations thermodynamic parameters such as change in free energy $\left(\Delta G^{\circ}\right)$, enthalpy $\left(\Delta H^{\circ}\right)$ and entropy $\left(\Delta S^{\circ}\right)$ were determined (Romero-Gonzalez et al. 2006).

$\Delta G^{\circ}=-R T \ln K_{\mathrm{c}}$

where $R$ gas constant $(R=8.314 \mathrm{~J} / \mathrm{mol} / \mathrm{K}), T$ temperature in Kelvin, $K_{\mathrm{c}}$ equilibrium constant

$K_{\mathrm{c}}=\frac{q_{\mathrm{e}}}{C_{\mathrm{e}}}$

where as

$\Delta G^{\circ}=\Delta H^{\circ}-T \Delta S^{\circ}$

Substituting the Eq. (14) in Eq. (12) and rearranging, yields the following equation:

$\ln K_{\mathrm{c}}=\left(\frac{\Delta H^{\circ}}{R}\right) \frac{1}{T}+\frac{\Delta S^{\circ}}{R}$.

Using the Khan and Singh plots ( $\ln q_{\mathrm{e}} / C_{\mathrm{e}}$ versus $q_{\mathrm{e}}$ ) the $K_{\mathrm{c}}$ was calculated. The enthalpy and entropy were obtained 
from the slope and intercept of $\ln K_{\mathrm{c}}$ versus $1 / T$ (Van-Hoff plot) (Romero-Gonzalez et al. 2006).

Desorption and regeneration studies

Elution of adsorbed metal ions from biosorbents and reusability of MLP consecutive adsorption-desorption cycles were repeated five times using the same MLP. Desorption experiments were conducted in $0.1 \mathrm{~N} \mathrm{HCl}$ and $0.1 \mathrm{~N} \mathrm{NaOH}$ solutions. The MLP loaded with $\mathrm{Cr}(\mathrm{VI})$ ions was placed in the desorption medium, and the mixture was agitated on a rotary shaker at $70 \mathrm{rpm}$ for a period of $30 \mathrm{~min}$. The MLP was removed by filtration and $\mathrm{Cr}(\mathrm{VI})$ concentration was determined in the filtrate. After each cycle of adsorption-desorption, the MLP was washed with distilled water and conditioned for adsorption in the subsequent cycle. The percent desorption was calculated based on the amount of $\mathrm{Cr}(\mathrm{VI})$ adsorbed on the MLP (at equilibrium stage) and the amount of metal ion concentration in the desorption medium.

\section{Results and discussion}

\section{Effect of particle size on $\mathrm{Cr}(\mathrm{VI})$ removal}

Adsorption of $\mathrm{Cr}(\mathrm{VI})$ on MLP increased with decreased particle size $1.4-0.5 \mathrm{~mm}$, then decreased proportionately with further reduction in particle size reduced (Fig. 1). The amount of $\mathrm{Cr}(\mathrm{VI})$ adsorption increased from 13.07 to $18.95 \mathrm{mg} / \mathrm{g}$ at $\mathrm{pH} 3$ with decreased particle size from 1.4 to $0.5 \mathrm{~mm}$. The increased adsorption with decreased particle size is attributed to the fact that smaller particle size has more surface area than the larger particles. However, fine particles $(<0.5 \mathrm{~mm})$ form an agglomerate in the solution and decrease the overall surface area which results in lesser uptake of metals (Hamadia et al. 2001). Hamadia et al. (2001) also observed a decrease in $\mathrm{Cr}$ (VI) adsorption as the average particle size was increased from 0.38 to $0.9 \mathrm{~mm}$, which in agreement with the current results.

\section{Effect of $\mathrm{pH}$ on chromium removal}

$\mathrm{pH}$ of the solution is of greater importance in heavy metal sorption (Hamadia et al. 2001). This is because $\mathrm{H}^{+}$or $\mathrm{OH}^{-}$ ions influence the ionization capacity of the metal ion present in it (Kumar and Chakraborty 2009). To investigate the effect of $\mathrm{pH}$ on the chromium removal using MLP, studies were conducted at $\mathrm{pH}$ range of $2-8$ and $100 \mathrm{mg} / \mathrm{L}$ chromium solution with $4 \mathrm{~g} / \mathrm{L}$ biomass. It was observed that the adsorption was the highest $(23.75 \mathrm{mg} / \mathrm{g})$ at $\mathrm{pH} 2$ and decreased with the increasing $\mathrm{pH}$. Increasing the solution $\mathrm{pH}$ from 2 to 8 , resulted in a decrease in the adsorption of $\mathrm{Cr}$ (VI) from 23.75 to $9.02 \mathrm{mg} / \mathrm{g}$ (Fig. 2). By changing the solution $\mathrm{pH}$ from 3 to 2 the adsorption efficiency was increased from 84 to $95 \%$. It is evident from the data represented in Fig. 2 that the chromium sorption is influenced by $\mathrm{pH}$ of the solution.

The surface of any biological materials contains several diverse active sites. The metal adsorption depends on these active sites as well as on the nature of metal ions in the solution. The higher chromium sorption by this material at lower $\mathrm{pH}$ may be attributed to the fact that the large number of hydrogen ions can easily co-ordinate with the $-\mathrm{NH}_{2}$ and $\mathrm{C}=\mathrm{O}$ groups present on the biomass surface. $\mathrm{Cr}(\mathrm{VI})$ is an anionic species, and as the biomass surface is positively charged, increasing electrostatic attraction between negatively charged sorbate and adsorbent might have resulted in the increased adsorption of metal ions. With increase in $\mathrm{pH}$ the adsorbent surface became more negatively charged which enhances the repulsions of sorbent ions (Malkoc and Nuhoglu 2007).

\section{Effect of chromium ion concentration on biosorption} of $\mathrm{Cr}(\mathrm{VI})$

The biomass potential of chromium removal was further evaluated by studying the chromium ion concentration range of 100-600 mg/L using $4 \mathrm{~g} / \mathrm{L} \mathrm{MLP}$ at pH 2 (Fig. 3). The adsorption capacity of MLP was increased up to the sorbent concentration $400 \mathrm{mg} / \mathrm{L}$. Further a decreased adsorption was noticed with increasing metal concentration. The uptake capacity of MLP increased from 22.99 to $43.43 \mathrm{mg} / \mathrm{L}$ by increasing $\mathrm{Cr}(\mathrm{VI})$ concentration from 100 to $400 \mathrm{mg} / \mathrm{L}$. However, the present adsorption decreased from 91.97 to $43.43 \%$ with increase in the sorbent

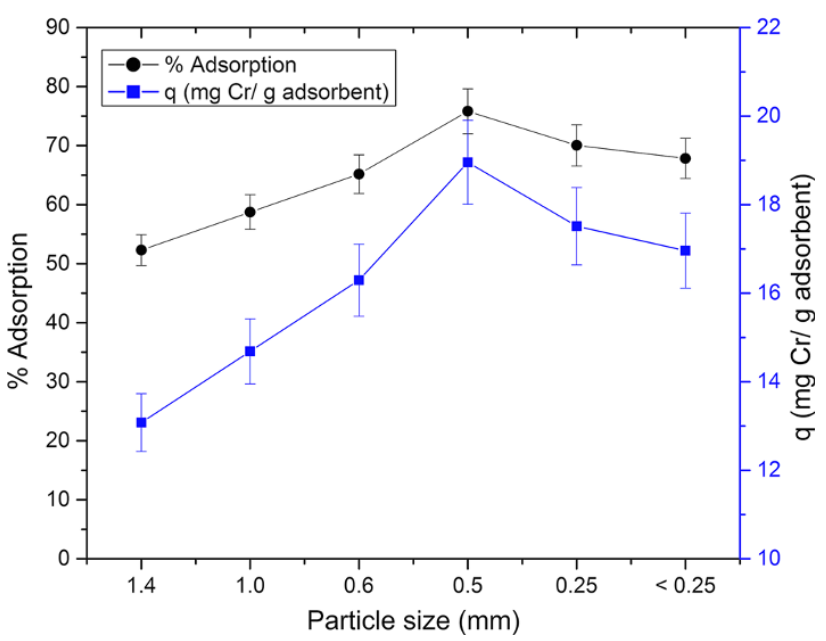

Fig. 1 Effect of particle size of mangrove leaf powder on $\mathrm{Cr}(\mathrm{VI})$ adsorption at $\mathrm{Cr}(\mathrm{VI})$ ion concentration $100 \mathrm{mg} / \mathrm{L}, \mathrm{pH} 3$ and adsorbent dose of $4 \mathrm{~g} / \mathrm{L}$ 


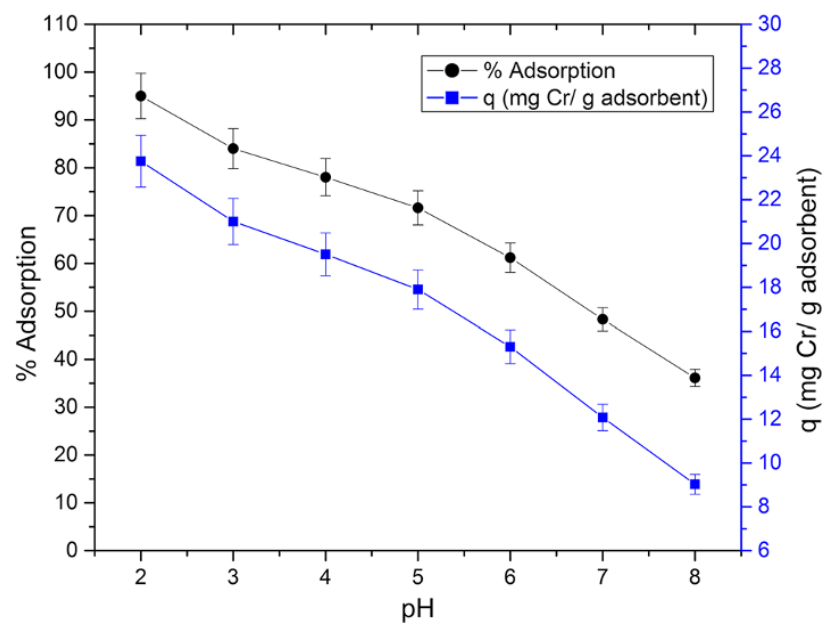

Fig. 2 Effect of $\mathrm{pH}$ on chromium sorption onto mangrove leaf powder at $\mathrm{Cr}(\mathrm{VI})$ concentration of $100 \mathrm{mg} / \mathrm{L}$, adsorbent dose of $4 \mathrm{~g} / \mathrm{L}$ and particle size $=0.5$

concentration to $400 \mathrm{mg} / \mathrm{L}$. The decreased adsorption at higher concentration may be due to the saturation of binding sites and increase in repulsion forces on sorbent ions (Malkoc and Nuhoglu 2007).

While increasing the $\mathrm{Cr}$ ion concentration from 100 to $300 \mathrm{mg} / \mathrm{L}$ for $4 \mathrm{~g} / \mathrm{L}$ of MLP recorded an increase in the adsorption capacity. At $400 \mathrm{mg} / \mathrm{L} \mathrm{Cr}(\mathrm{VI})$ on the same quantity of MLP, the $\mathrm{Cr}$ ions covered all available binding surface of MLP that leads to saturation, which creates non-availability of cations on sorbent that leads to repulsion of $\mathrm{Cr}(\mathrm{VI})$ anions from further addition at $400 \mathrm{mg} / \mathrm{L}$ which decreases the adsorption capacity. The adsorption isotherms (Freundlich and Langmuir isotherms) also reveal that $\mathrm{Cr}(\mathrm{VI})$ adsorbs as a monolayer on the surface of MLP.

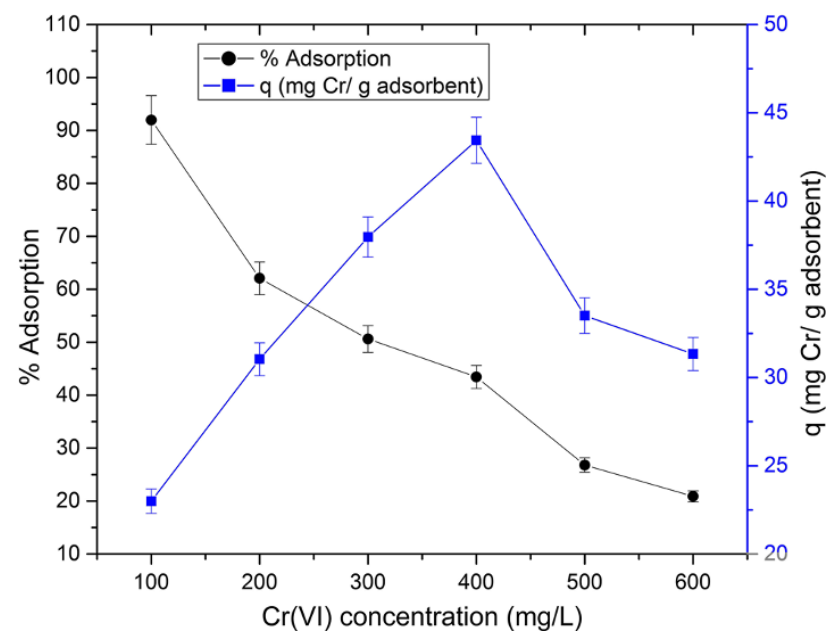

Fig. 3 Effect of initial $\mathrm{Cr}(\mathrm{VI})$ concentration on sorption onto mangrove leaf powder $(\mathrm{pH} 2$, adsorbent dose $=4 \mathrm{~g} / \mathrm{L}$, particle size $=0.5)$
Effect of biomass variation on chromium removal

Another important parameter that affects the biosorption process is the amount of adsorbent used (Malkoc and Nuhoglu 2007). From the data of Fig. 4, it is evident that the percent $\mathrm{Cr}(\mathrm{VI})$ removal was increased from 27.35 to $92.15 \%$ with an increasing MLP concentration from 2 to $10 \mathrm{~g} / \mathrm{L}$. With the increasing MLP concentration, the uptake capacity of metal ions decreased from 54.71 to $36.85 \mathrm{mg} / \mathrm{g}$. This is attributed to the fact that due to higher amounts of MLP increase the surface area made available more adsorption sites resulting in higher removal of $\mathrm{Cr}(\mathrm{VI})$.

\section{Adsorption kinetics}

In the present study for a batch reaction, the adsorption dynamics were determined using the Eqs. (1), (5)-(7). Table 1 depicts the comparison of various constants obtained with the correlation coefficients. Good fits were observed for all particle sizes. The smallest correlation coefficient (0.8308) was observed with the $1.4 \mathrm{~mm}$ particle size of MLP at second order. Except particle size of $1.4 \mathrm{~mm}$, the remaining particles' sorption reaction can be approximated with the second-order kinetics model. It can be observed that the initial sorption rate $(h)$ is higher at particle size at $0.5 \mathrm{~mm}$ than others. The change in rate constants depending on the particle size shows that particle size is a rate-limiting step for surface adsorption of $\mathrm{Cr}(\mathrm{VI})$ by MLP.

\section{Adsorption isotherms}

The linearized form of Freundlich and Langmuir adsorption isotherms of $\mathrm{Cr}(\mathrm{VI})$ by MLP was obtained at the temperatures of 10,25 and $40{ }^{\circ} \mathrm{C}$. Figures 5 and 6 show the linearized Freundlich and Langmuir adsorption isotherms. The

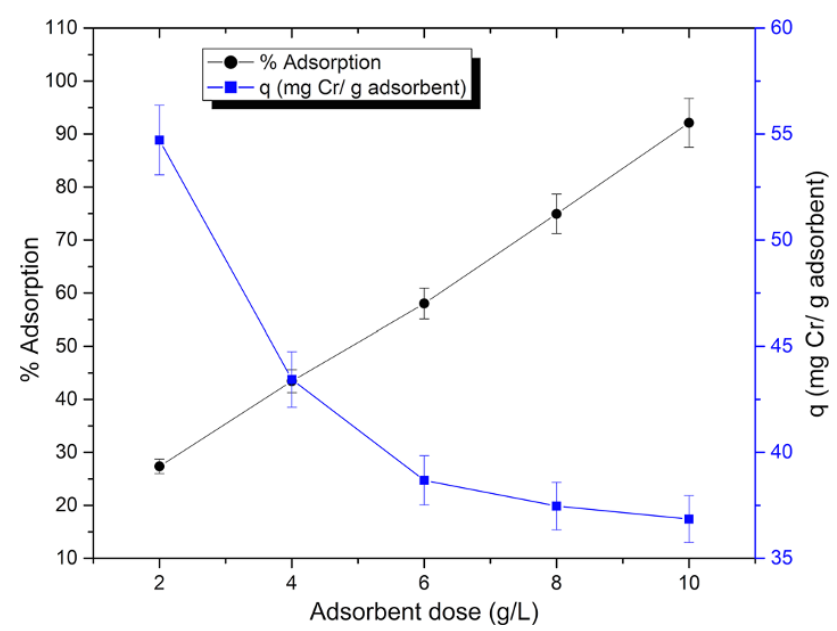

Fig. 4 Effect of adsorbent dose on sorption of $\mathrm{Cr}(\mathrm{VI})$ onto mangrove leaf powder $(\mathrm{pH} 2$, particle size $=0.5, \mathrm{Cr}(\mathrm{VI})=400 \mathrm{mg} / \mathrm{L})$ 
Table 1 The first-order, pseudo first-order and pseudo second-order rate constants for mangrove leaf powder at different particle sizes

\begin{tabular}{|c|c|c|c|c|c|}
\hline & \multicolumn{5}{|c|}{ Particle size $(\mathrm{mm})$} \\
\hline & 1.4 & 1.0 & 0.6 & 0.5 & 0.25 \\
\hline \multicolumn{6}{|c|}{ First-order kinetics } \\
\hline$k_{\mathrm{r}}^{\prime}(1 / \mathrm{min})$ & 0.1190 & 0.0875 & 0.1545 & 0.1233 & 0.1372 \\
\hline$K_{\mathrm{c}}$ & 1.1366 & 1.4502 & 1.9856 & 24.0466 & 8.0160 \\
\hline$k_{1}(1 / \mathrm{min})$ & 0.0633 & 0.0517 & 0.1027 & 0.1183 & 0.1219 \\
\hline$k_{2}(1 / \mathrm{min})$ & 0.0556 & 0.0357 & 0.0517 & 0.0049 & 0.0152 \\
\hline$R^{2}$ & 0.9600 & 0.9335 & 0.9017 & 0.9655 & 0.9321 \\
\hline \multicolumn{6}{|c|}{ Pseudo first-order kinetics } \\
\hline$k_{1}^{\prime}(1 / \min )$ & 0.1119 & 0.0875 & 0.1545 & 0.1234 & 0.1372 \\
\hline$R^{2}$ & 0.9600 & 0.9334 & 0.9017 & 0.9655 & 0.9321 \\
\hline \multicolumn{6}{|c|}{ Pseudo second-order kinetics } \\
\hline$k_{2}^{\prime}(\mathrm{g} / \mathrm{mg} \min )$ & 0.0299 & 0.0556 & 0.0623 & 0.0871 & 0.0691 \\
\hline$h(\mathrm{mg} / \mathrm{g} \min )$ & 0.0084 & 0.0195 & 0.0275 & 0.0802 & 0.0546 \\
\hline$R^{2}$ & 0.8308 & 0.9641 & 0.9499 & 0.9738 & 0.9471 \\
\hline
\end{tabular}

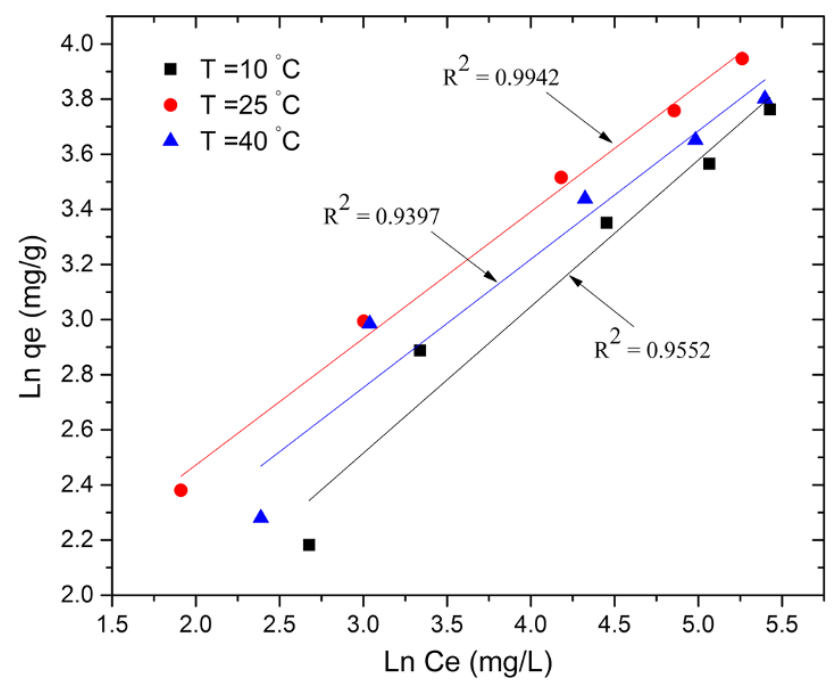

Fig. 5 Freundlich isotherm plot for the adsorption of chromium onto mangrove leaf powder at various temperatures $\left(C_{\mathrm{e}}\right.$ equilibrium concentration, $q_{\mathrm{e}}$ amount of $\mathrm{Cr}(\mathrm{VI})$ adsorbed)

Freundlich and Langmuir adsorption constants estimated from the isotherms at different temperatures and their correlation coefficients are presented in Table 2 . The constant values derived from adsorption isotherm could express the surface properties and affinity of adsorbent. These constant values can also be useful to determine the adsorption capacity of the sorbent (Malkoc and Nuhoglu 2007).

The correlation coefficient values obtained from the Freundlich and Langmuir isotherms indicate that the adsorption pattern for $\mathrm{Cr}(\mathrm{VI})$ on MLP follows both the Freundlich isotherm $\left(R^{2}>0.9397\right)$ and the Langmuir isotherm $\left(R^{2}>0.9824\right)$ at all experimental temperatures

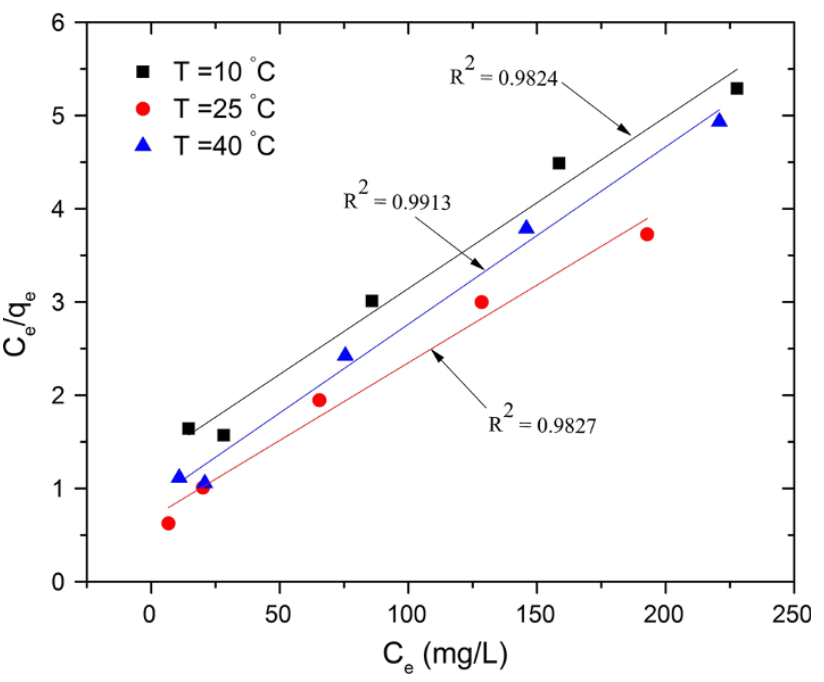

Fig. 6 Langmuir plots for the adsorption of chromium onto mangrove leaf powder at various temperatures $\left(C_{\mathrm{e}}\right.$ equilibrium concentration, $q_{\mathrm{e}}$ amount of $\mathrm{Cr}(\mathrm{VI})$ adsorbed)

Table 2 Freundlich and Langmuir constants for the adsorption of $\mathrm{Cr}(\mathrm{VI})$ onto mangrove leaf powder at different temperatures and $\mathrm{pH} 2$

\begin{tabular}{|c|c|c|c|}
\hline & \multicolumn{3}{|c|}{ Temperature $\left({ }^{\circ} \mathrm{C}\right)$} \\
\hline & 10 & 25 & 40 \\
\hline \multicolumn{4}{|c|}{ Freundlich constants } \\
\hline$K_{\mathrm{f}}(\mathrm{mg} / \mathrm{g})$ & 2.1552 & 3.6544 & 3.1006 \\
\hline$n$ & 1.8807 & 2.1767 & 2.1477 \\
\hline$R^{2}$ & 0.9552 & 0.9942 & 0.9397 \\
\hline \multicolumn{4}{|c|}{ Langmuir constants } \\
\hline$Q^{0}(\mathrm{mg} / \mathrm{g})$ & 54.3478 & 60.2409 & 52.6315 \\
\hline$b(1 / \mathrm{mg})$ & 0.0141 & 0.0243 & 0.0221 \\
\hline$R^{2}$ & 0.9824 & 0.9827 & 0.9913 \\
\hline \multicolumn{4}{|l|}{$R_{\mathrm{L}}$ values } \\
\hline \multicolumn{4}{|l|}{$C_{\mathrm{o}}(\mathrm{mg} / \mathrm{L})$} \\
\hline 50 & 0.5864 & 0.4514 & 0.4748 \\
\hline 100 & 0.4149 & 0.2915 & 0.3113 \\
\hline 200 & 0.2617 & 0.1706 & 0.1843 \\
\hline 300 & 0.1911 & 0.1206 & 0.1309 \\
\hline 400 & 0.1505 & 0.0932 & 0.1015 \\
\hline
\end{tabular}

(Table 2). However, the Langmuir isotherm was best fitted for the adsorption of chromium ions on MLP at studied temperatures. It has been known that the magnitude of Freundlich model constant $K_{\mathrm{f}}$ indicates a measure of the adsorbent capacity. Among the studied temperatures, the maximum adsorption capacity $\left(K_{\mathrm{f}}\right)$ of $3.6544 \mathrm{mg} / \mathrm{g}$ was observed at $25^{\circ} \mathrm{C}$ with an affinity value $(n)$ of 2.1767 . As indicated in Table 2, the affinity values $(n)$ range 1.8-2.2 indicating a favorable adsorption of $\mathrm{Cr}(\mathrm{VI})$ on MLP. 
According to Langmuir isotherm the equilibrium adsorption capacity $\left(Q^{0}\right)$ of MLP increased from 54.34 to $60.24 \mathrm{mg} / \mathrm{g}$ with increase in the solution temperature from 10 to $25^{\circ} \mathrm{C}$. However, the adsorption capacity decreased from 25 to $40{ }^{\circ} \mathrm{C}$ (Table 2). The sorption constant ' $b$ ' also follows a similar pattern. From the Langmuir isotherm it is clear that the sorption of chromium on MLP is an endothermic process (Malkoc and Nuhoglu 2007).

The separation factor or equilibrium parameter $\left(R_{\mathrm{L}}\right)$ is a feature of Langmuir isotherm; it is a dimensionless constant and relates the isotherm shape which is used to predict whether a sorption system is 'favorable' or 'unfavorable'. Where $R_{\mathrm{L}}>1$ the isotherm is unfavorable, if $R_{\mathrm{L}}=1$ the isotherm is linear, if $0<R_{\mathrm{L}}<1$ the isotherm is favorable and if the $R_{\mathrm{L}}=0$ the isotherm is irreversible (Malkoc and Nuhoglu 2007). The various $R_{\mathrm{L}}$ values obtained at different temperatures relating to initial chromium concentration are presented in Table 2 . In the present study $R_{\mathrm{L}}$ values decreased with increasing initial $\mathrm{Cr}(\mathrm{VI})$ concentration at all studied temperatures. This indicates that sorption of $\mathrm{Cr}(\mathrm{VI})$ on MLP is more favorable at higher initial $\mathrm{Cr}(\mathrm{VI})$ concentrations. According to Das et al. (2000), any adsorption system which obeys both the Freundlich and Langmuir isotherms indicates that the solute forms a homogenous monolayer on the adsorbate. In the current study, the adsorption of $\mathrm{Cr}(\mathrm{VI})$ onto MLP obeyed both Freundlich and Langmuir isotherms suggesting that the $\mathrm{Cr}(\mathrm{VI})$ forms a monolayer on the surface of MLP.

\section{Thermodynamic studies}

Table 3 depicts various thermodynamic parameters calculated in the present study. The data indicated negative $\Delta G^{\circ}$ values suggesting spontaneous nature of $\mathrm{Cr}$ adsorption on the MLP. The enthalpy change $\left(\Delta H^{\circ}\right)$ and the entropy change $\left(\Delta S^{\circ}\right)$ were calculated to be $41.92 \mathrm{~kJ} / \mathrm{mol}$ and $138.53 \mathrm{~J} / \mathrm{mol} / \mathrm{K}$, respectively. The positive value of $\Delta H^{\circ}$ suggested that the adsorption is of endothermic nature. The positive value of $\Delta S^{\circ}$ showed increased randomness at the solid/solution interface during the adsorption process, suggesting that the $\mathrm{Cr}$ ions replace some other molecules previously adsorbed on the surface of MLP. This may be explained based on the assumption that, the displaced molecules (may be water or other ions) gain more translation entropy than is lost by the $\mathrm{Cr}$ ions, thus allowing the prevalence of randomness in the system (Malkoc and $\mathrm{Nu}$ hoglu 2007).

Desorption and regeneration studies

Disposal of $\mathrm{Cr}(\mathrm{VI})$ loaded biosorbents in the environment is hazardous to the nature. Desorption of metals from sorbent helps in recovery of metals and reduces the
Table 3 Thermodynamic parameters for the adsorption of $\mathrm{Cr}(\mathrm{VI})$ onto mangrove leaf powder

\begin{tabular}{lllll}
\hline$T(\mathrm{~K})$ & $K_{\mathrm{c}}$ & $\Delta G^{\circ}(\mathrm{kJ} / \mathrm{mol})$ & $\Delta H^{\circ}(\mathrm{kJ} / \mathrm{mol})$ & $\Delta S^{\circ}(\mathrm{J} / \mathrm{mol} / \mathrm{K})$ \\
\hline 283 & 0.0127 & -10.2735 & 41.92 & 138.53 \\
298 & 0.897 & -0.26932 & & \\
303 & 0.5752 & -1.39325 & & \\
\hline
\end{tabular}

Table 4 Adsorption and desorption of $\mathrm{Cr}(\mathrm{VI})$ onto mangrove leaf powder (adsorbent dose $=4 \mathrm{~g} / \mathrm{L}, \quad$ particle $\quad$ size $=0.5$, $\mathrm{Cr}(\mathrm{VI})=400 \mathrm{mg} / \mathrm{L})$

\begin{tabular}{llllll}
\hline Cycle no. & 1 & \multicolumn{1}{l}{ 2 } & \multicolumn{1}{l}{4} & \multicolumn{1}{l}{5} \\
\hline Cr adsorbed (mg/g) & 51.77 & 47.94 & 38.70 & 36.41 & 35.47 \\
Cr desorbed (mg/g) & 48.85 & 40.83 & 28.28 & 26.23 & 24.88 \\
\% Adsorption decreased & - & 7.40 & 25.25 & 29.67 & 31.49 \\
\% Desorption & 94.34 & 85.16 & 73.07 & 72.03 & 70.13 \\
\hline
\end{tabular}

disposal problem of metal-loaded sorbents. The regeneration capability of the biosorbent is one of the important parameter for considering their potential for commercialization. In the present study high amount of $\mathrm{Cr}(\mathrm{VI})$ was desorbed in the $0.1 \mathrm{~N} \mathrm{HCl}$ solution compared with $0.1 \mathrm{~N}$ $\mathrm{NaOH}$. Desorption studies showed that initially $94.34 \%$ of $\mathrm{Cr}(\mathrm{VI})$ was desorbed from MLP, in subsequent cycles decreased desorption was noticed. At 5th cycle $70.13 \%$ desorption was observed (Table 4). However, the adsorption capacity of MLP was decreased from 51.77 (1st cycle) to $35.37 \mathrm{mg} / \mathrm{g}$ (5th cycle). An overall $31.49 \%$ reduction in the adsorption capability of MLP was observed at 5th cycle. The decreased adsorption and desorption during the repeated cycles attributed due to structural changes on the surface of sorbent and some of metal ions being held in the intrapores of MLP (Kaur et al. 2013). Kaur et al. (2013) observed that complete desorption of metal ions from the surface of agricultural residues is not possible even at high acid concentrations.

\section{Conclusion}

This study demonstrated that MLP could be used as an important component for the remediation of hexavalent chromium. It is an environmental friendly technology for cleaning-up the chromium-contaminated waste waters. The optimal operating conditions under laboratory conditions were evaluated. This study as well reveals that chromium sorption is affected by particle size of MLP, $\mathrm{pH}$ of the solution, concentration of sorbent and adsorption dose. The sorption isotherm studies revealed heterogeneous energetic distribution of chromium adsorption active sites on this material. Thermodynamic studies indicated that the 
chromium sorption by this material is spontaneous in nature. Based on this study, it is rational to conclude that the use of natural and abundantly available materials best suits to immobilize and detoxify toxic compounds, such as chromium.

Acknowledgments The authors gratefully acknowledge the financial support provided by the Ministry of Earth Science (MOES), Government of India, to conduct this research. We are thankful to Dr. M. A. Atmanand, Director, Earth System Science Organization (ESSO), National Institute of Ocean Technology, MOES for constant encouragement to conduct this work.

Open Access This article is distributed under the terms of the Creative Commons Attribution License which permits any use, distribution, and reproduction in any medium, provided the original author(s) and the source are credited.

\section{References}

Acar FN, Malkoc E (2004) The removal of chromium(VI) from aqueous solutions by Fagus orientalis L. Bioresour Technol 94(1):13-15

APHA (1985) Standard methods for the examination of waste and wastewater, 16th edn. American Public Health Association, Washington, DC

Baral A, Engelken RD (2002) Chromium-based regulations and greening in metal finishing industries in the USA. Environ Sci Policy 5:121-133

Cay S, Uyanık A, Özaşık A (2004) Single and binary component adsorption of copper(II) and cadmium(II) from aqueous solutions using tea-industry waste. Sep Purif Technol 38:273-280

Cerbasi IH, Yetis U (2001) Biosorption of Ni (ii) and Pb (ii) by Phanerochaete chrysosporium from binary metal systemkinetics. Water Res 27:15-20

Costa M (2003) Potential hazards of hexavalent chromate in our drinking water. Toxicol Appl Pharm 188:1-5

Daneshvar N, Salari D, Aber S (2002) Chromium adsorption and $\mathrm{Cr}(\mathrm{VI})$ reduction to trivalent chromium in aqueous solutions by soya cake. J Hazard Mater 94(1):49-61

Das D, Mahapatra R, Pradhan J, Das SN, Thakur RS (2000) Removal of $\mathrm{Cr}(\mathrm{VI})$ from solution using activated cow dung carbon. J Colloid Interface Sci 232:235-240

Gupta VK, Ali I (2004) Removal of lead and chromium from wastewater using bagasse fly ash-a sugar industry waste. J Colloid Interface Sci 271:321-328

Gupta VK, Srivastava AK, Jain N (2001) Biosorption of chromium(VI) from aqueous solutions by green algae Spirogyra species. Water Res 35:4079-4085

Hamadia NK, Chen XD, Farid MM, Lub MGQ (2001) Adsorption kinetics for the removal of chromium(VI) from aqueous solution by adsorbents derived from used tyres and sawdust. Chem Eng J 84:95-105

Ho YS, Chiang TH, Hsueh YM (2005) Removal of basic dye from aqueous solution using tree fern as a biosorbent. Process Biochem 40(1):119-124

Kadimpati KK, Mondithoka KP, Bheemaraju S, Challa VRM (2013) Entrapment of marine microalga, Isochrysis galbana, for biosorption of $\mathrm{Cr}$ (III) from aqueous solution: isotherms and spectroscopic characterization. Appl Water Sci 3:85-92

Kaur R, Singh J, Khare R, Cameotra SS, Ali A (2013) Batch sorption dynamics, kinetics and equilibrium studies of $\mathrm{Cr}(\mathrm{VI}), \mathrm{Ni}(\mathrm{II})$ and $\mathrm{Cu}$ (II) from aqueous phase using agricultural residues. Appl Water Sci 3:207-218

Krishna KR, Philip L (2005) Bioremediation of Cr(VI) in contaminated soils. J Hazard Mater B 121:109-117

Kumar PA, Chakraborty S (2009) Fixed-bed column study for hexavalent chromium removal and recovery by short-chain polyaniline synthesized on jute fiber. J Hazard Mater 162:2-3

Kurniawan TA, Chan GYS, Lo W-H, Babel S (2006) Physicochemical treatment techniques for wastewater laden with heavy metals. Chem Eng J 118:83-98

Malkoc E, Nuhoglu Y (2003) The removal of chromium(VI) from synthetic wastewater by Ulothrix zonata. Fresenius Environ Bull $12: 376-381$

Malkoc E, Nuhoglu Y (2005) Investigations of nickel(II) removal from aqueous solutions using tea factory waste. J Hazard Mater 127(1-3):120-128

Malkoc E, Nuhoglu Y (2006) Removal of Ni(II) ions from aqueous solutions using tea factory waste: adsorption on a fixed-bed column. J Hazard Mater 135(1-3):328-336

Malkoc E, Nuhoglu Y (2007) Potential of tea factory waste for chromium(VI) removal from aqueous solutions: thermodynamic and kinetic studies. Sep Purif Technol 54:291-298

Park D, Yun Y-S, Park JM (2005) Use of dead fungal biomass for the detoxification of hexavalent chromium: screening and kinetics. Process Biochem 40:2559-2565

Prakasham RS, Merrie JS, Sheela R, Saswathi N, Ramakrishna SV (1999) Biosorption of chromium VI by free and immobilized Rhizopus arrhizus. Environ Pollut 104:421-427

Romero-Gonzalez J, Peralta-Videa JR, Rodriguez E, Delgado M, Gardea-Torresdey JL (2006) Potential of Agave lechuguilla biomass for $\mathrm{Cr}(\mathrm{III})$ removal from aqueous solutions: thermodynamic studies. Bioresour Technol 97(1):178-182

Rozaini CA, Jain K, Tan KWOCW, Tan LS, Azraa A, Tong KS (2010) Optimization of nickel and copper ions removal by modified mangrove barks. Int J Chem Eng Appl 1(1):84-89

Selvaraj K, Manonmani S, Pattabhi S (2003) Removal of hexavalent chromium using distillery sludge. Bioresour Technol 89(2):207-211

Yu LJ, Shukla SS, Dorris KL, Shukla A, Margrave JL (2003) Adsorption of chromium from aqueous solutions by maple sawdust. J Hazard Mater 100(1-3):53-63 